INT'L. J. PSYCHIATRY IN MEDICINE, Vol. 31(3) 321-336, 2001

\title{
RELIGION AND MEDICINE IV: RELIGION, PHYSICAL HEALTH, AND CLINICAL IMPLICATIONS
}

HAROLD G. KOENIG, M.D.

Duke University Medical Center and

GRECC, VA Medical Center, Durham, North Carolina

\begin{abstract}
In the fourth and final article of this religion and medicine series, I summarize the results of a comprehensive and systematic review of research examining religion's relationship to physical health and mortality. This review focuses on pain and disability, cardiovascular disease, immune and neuroendocrine function, susceptibility to infection, cancer, and overall mortality. I also explore what these research findings mean for medical practice and suggest patient-centered applications that are sensitive to ethical concerns.
\end{abstract}

(Int'l. J. Psychiatry in Medicine 2001;31:321-336)

Key Words: religion, spirituality, pain, disability, immunity, cancer, longevity

In the third article of this series, I presented a theoretical model explaining how religious beliefs and practices might impact physical health. In this final article, I discuss research that has tested the validity of this model. That research was identified during a comprehensive systematic review of the literature over the past century as described in the second article of this series. To summarize, a threestage process was used to identify relevant studies. First, we performed computer searches of the literature to identify quantitative studies of the religion-physical health relationship. Second, we consulted the footnotes and references of articles retrieved by the search to identify other relevant studies, repeating this process until no new studies could be found. Third, we examined review articles and books 
on the topic. Proceeding in this manner, we identified over 225 reports on religion and pain/disability, heart disease, blood pressure, stroke, immune/neuroendocrine function, infectious disease, cancer, and overall mortality. A description of each of the studies referred to in this section can be found elsewhere [1].

\section{PAIN AND FUNCTIONAL DISABILITY}

Ten studies have examined the relationship between religion and pain, with the majority focusing on the relationship between prayer and pain intensity. Four of six cross-sectional studies found that frequent prayer was associated with greater pain intensity. These results may be interpreted in at least two ways. First, pain may lead to increased prayer as the person attempts to cope with the pain. Prayer is a response to the pain. Second, prayer may lead to increased pain because it somehow focuses the mind on the pain. Also, if praying fails to bring relief of pain, the person may be so disappointed and discouraged that the pain appears to worsen. Thus, prospective studies and clinical trials are needed to help determine whether prayer increases in response to pain or whether pain increases in response to prayer.

The only true prospective study that has been done found that "praying and hoping" was positively related to greater pain at baseline, as in previous studies. When subjects were assessed over time, however, increased prayer predicted significantly lower pain levels 8 weeks later [2]. Similarly, Kabat-Zinn and colleagues [3] found that prayer/meditation when used as an intervention for treating chronic pain resulted in a significant lowering of pain over time. A third study examined the effects of a standard chaplain intervention on requests for "prn" pain medication following orthopedic surgery. This study found significantly fewer requests by patients receiving the intervention compared to control patients [4]. These three studies suggest that the positive cross-sectional correlations between prayer/religious activities and pain are a likely result of increased praying in response to pain. Prayer over time may either reduce pain level or help the person to cope better with it. This does not mean, however, that prayer always helps to reduce pain or enables people to cope better with it; but in many cases, this does apparently occur.

With regard to functional disability and religious involvement, 12 studies were identified. Idler and Kasl [5-8] have done some of the best work in this area. These investigators report over a decade of research following 2812 older adults participating in the Yale-New Haven EPESE survey. In their latest report, Idler and Kasl [8] found evidence that frequent religious attendance delayed the onset and progression of physical disability in their older sample. More important, given the concern that physical disability may confound the relationship between religious activity and health, physical disability had much less of an effect on preventing religious attendance than did attendance on preventing physical disability. 
While religious attendance predicted less future disability, investigators found that personal religiousness or level of comfort derived from religion did not. This relationship, however, may also be a complex one. As physical illness and disability worsen, people often turn to religion for comfort, as noted with increasing pain, possibly disguising some of the long-term benefits that personal religious faith may convey. In fact, there is some evidence that personal religiousness may positively influence the perception of disability. Idler [5] discovered that for any given level of chronic illness, men with high levels of private religiousness reported less disability than did men with lower levels of religiousness. In order to explain this association, she conducted another study [9] in which she found that a person's subjective rating of health represents broad conceptions of self in which actual physical health may be de-emphasized and nonphysical characteristics-i.e., religious or spiritual self-identities and wellbeing - are relied on more heavily.

\section{HEART DISEASE}

The review identified 32 quantitative studies, 16 examining differences in heart disease across religious denominations and 16 examining level of religiousness and heart disease. Of the 16 studies examining the relationship between religious denomination and heart disease, four found higher rates of CAD in Jews compared with non-Jews and one study showed higher rates in Ashkenazi compared with Oriental Jews. The highest rates of CAD were found among secular Jews [10-12].

Of the 16 studies examining religiousness and heart disease, 12 (75 percent) found less heart disease or lower cardiovascular mortality among the more religious; 3 studies found no association; 1 study reported mixed findings (but measured parental affiliation only). Two were prospective cohort studies that measured religiousness at baseline and followed subject over time assessing outcomes $[12,13]$. Both found greater religiousness predicted lower mortality. Five studies were clinical trials that included a religious/spiritual component as part of a psychosocial-behavioral intervention (including prayer, yoga, or transcendental meditation); all five reported positive effects [14-18].

\section{BLOOD PRESSURE}

The review identified 34 studies that examined the relationship between religion and blood pressure. Of those, 16 assessed level of religiousness, 4 compared blood pressures in Seventh-Day Adventists with others, one study compared Protestants, Catholics, and Jews, and 13 studies were clinical trials where a religious or spiritual intervention (usually meditation) was used to treat high blood pressure. No fewer than 14 of 16 studies that assessed the relationship between level of religiousness and blood pressure found lower blood pressure among the more religious. In these studies, diastolic blood pressure in particular 
was lower in religious compared with non-religious subjects. In all studies that correlated measured blood pressures with religiousness-including both prospective cohort studies - subjects who were more religious had significantly lower blood pressures. Of the 13 clinical trials, 9 found that a spiritual intervention (7 involving meditation) lowered blood pressure.

\section{STROKE}

While six studies were located that quantitatively examined religion and stroke, five of these compared rates of stroke between members of a religious group and the general population. Only one study examined degree of religious involvement as a predictor of future stroke. Colantonio and colleagues [19] followed 2812 older adults, finding that subjects who attended religious services at least once/week were less likely than those attending services less frequently to have a stroke during the six-year follow-up (4.7 percent vs. 7.5 percent, $p<.001)$. When religious attendance was categorized as "once or twice/year or more" vs. "never," the effects of attendance lost statistical significance in a multivariate regression model that included other predictors like hypertension, myocardial infarction, and smoking. It is not surprising, however, that religious attendance lost statistical significance after investigators controlled for the likely mechanism of the effect (i.e., perhaps religious attenders experienced fewer strokes because they had lower blood pressures, fewer heart attacks, and were less likely to smoke cigarettes, as other studies have found).

\section{IMMUNE AND NEUROENDOCRINE FUNCTION}

The study of religion/spirituality, neuroendocrine, and immune function is in its infancy, and only the most tentative of hypotheses can be forwarded based on existing data. A total of five studies (three published) have examined the relationship between a measure of religious involvement and immune function. In the first study, McClelland [20] found that salivary IgA levels in 70 students watching a religious film were significantly higher than in 62 students watching a war film. In the second study (the first study to examine religious involvement and immune function), Koenig and colleagues [21] measured interleukin-6 (IL-6) and other biological indicators of inflammation in 1718 persons aged 65 or older. IL-6 levels were correlated with frequency of religious attendance. Those who attended religious services were 49 percent less likely than non-attenders to have high IL-6 levels ( $>5 \mathrm{pg} / \mathrm{ml})$. When age, sex, race, education, chronic illness, and physical functioning were controlled, the effect was reduced from 49 percent to 42 percent but remained significant $(p<.005)$. Not long after this report, Lutgendorf [22] examined plasma IL-6 levels in 55 older adults, also finding an inverse correlation with religious or spiritual coping (partial $r=-.26, p=.075$ after controlling for stress level). 
In the last published study, Woods and colleagues [23] surveyed 106 HIV sero-positive gay men to determine the relationship between religiosity and immune function. Religious activities, such as prayer, religious attendance, spiritual discussions, and reading religious/spiritual literature, were associated with significantly higher CD4+ counts and CD4+ percentages. Religious coping (putting trust in God, seeking God's help, increasing praying, etc.) was related to fewer depressive symptoms $(p<.01)$ and less anxiety $(p=.08)$, but not to specific immune markers. A fifth study by Schaal and colleagues at Stanford University examined correlations between religious involvement and immune function in 112 women with metastatic breast cancer [24]. Importance of religious or spiritual expression was positively correlated with NK cell numbers $(r=.19$, $p=.02)$, T-helper cell counts $(r=.16, p=.05)$, and total lymphocytes $(r=.15$, $p=.05$ ). Religious expression was unrelated to delayed-type hypersensitivity.

Religious involvement and neuroendocrine function has been examined in at least 11 studies. Nine of these studies assessed the effects of meditation or tai-chi on endocrine function, with seven finding that such practices reduced cortisol and other stress hormones at least temporarily. In the remaining two studies, the first reported that of 30 women awaiting breast biopsies for possible cancer, those who employed prayer and faith to cope tended to have lower cortisol levels than other women [25]. The second study, Schaal's examination of women with metastatic breast cancer [24], found that evening cortisol levels were significantly lower among women who scored higher on religious expression. The results of these immune and neuroendocrine studies, then, are consistent with the hypothesis that religious practices facilitate coping, thereby reducing stress-related hormone levels and improving immunity.

A series of clinical trials and epidemiologic studies are now being conducted at Johns Hopkins University's Center for Health Promotion (supported by NIH), Harvard's Mind-Body Medicine Institute (supported by CDC), and University of Miami (supported by NIH) to better understand the relationship between religious interventions, lifestyles and immune functioning in women with breast cancer, persons with congestive heart failure, the elderly with hypertension, and long-term survivors who are HIV positive or have AIDS.

\section{INFECTIOUS DISEASE}

Little research has examined whether religious activity decreases susceptibility to infection, and the studies that have been done only indirectly address this question. Kuemmerer and Comstock [26], studying a population-based sample of 7,787 junior and senior high school students in Washington County, Maryland, compared the characteristics of students with positive and negative TB skin tests. Investigators found that the frequency of large reactions was greater among children whose parents attended church less than once/month than among those whose parents went to church more often. Comstock and colleagues 
[27] next matched cases of active TB between 1960 and 1964 against the 1963 Washington County census data to obtain approximate five-year incidence rates. Persons who attended church at least weekly had the lowest five-year rates $(57 / 100,000)$, those who attended church once/month had intermediate rates $(84 / 100,000)$, and those who attended only twice a year or less had the highest rate $(138 / 100,000)$.

Only one study has examined the effects of religion on probability of contracting a sexually transmitted disease (STD). Again reporting from the Washington County (MD) study, Naguib and colleagues [28] conducted a large cytologic screening program involving 4,290 women. Among women claiming to have no religious affiliation and those refusing to answer this question, the prevalence of tests positive for trichomoniasis was 20 percent (significantly higher than 14.5 percent for the group as a whole). Among the 3,962 women designated as "Christians," frequent religious attendance was associated with lower rates of trichomoniasis: among those attending services once/week or more, 12.4 percent had trichomoniasis compared with 18.2 percent for those attending services once/month or less. These analyses did not control for education or income, although doing so would probably increase differences observed since religion tends to be more common among the poor and those with less education (who are also at greater risk for STDs).

\section{CANCER}

At least 13 studies have quantitatively examined the relationship between religion and risk of cancer. Ten of these compared the risk of cancer by religious denomination. Only three studies examined the effect of degree of religious involvement on cancer risk. Two of these reported lower rates of cervical cancer (or abnormal Pap smears) in the more religious [29, 30], and one found no difference in overall cancer risk [31].

With regard to cancer mortality, 36 studies have examined the relationship to religion. Again, most $(n=28)$ compared rates by religious denomination. As with cancer risk, a consistent finding was that Mormons and Seventh-Day Adventists lived longer than people in the general population. Of the remaining eight studies, seven examined the relationship between degree of religiousness and cancer mortality. Five of these found that greater religiousness predicted a lower likelihood of dying from cancer [32-36], and two studies found no effect [37, 38]. The remaining study was a randomized double-blind clinical trial of intercessory prayer conducted with a small sample of children with leukemia; no statistically significant difference in mortality $(p>.05)$ was found between those receiving the intervention (two of eight children died were 25 percent) and those in the control group ( 7 of 10 children died or 70 percent) [39]. 


\section{MORTALITY}

At least 101 studies have quantitatively examined the relationship between religion and mortality (including the 36 cancer mortality studies noted above). Forty-seven studies measured religious affiliation only, 52 assessed level of religiousness, and the remaining two studies were clinical trials. Of studies measuring religiousness, the most common measure was religious attendance ( 21 of 52 studies); 13 studies examined clergy mortality. The two clinical trials involved one study of transcendental meditation (TM) in elderly nursing home patients (demonstrating longer survival in the TM group) and a second study of intercessory prayer in children with leukemia (finding no association, as noted earlier). A consistent result among denominational studies was lower mortality among the Amish, Seventh-Day Adventists, Mormons, and to a lesser extent, Jews - compared to the general population.

Of the 52 studies that assessed level of religiousness, 39 found longer survival for those who were more religious, 10 found no association, 2 reported complex results, and 1 found shorter survival. Thus, three-quarters of studies found that greater religiousness predicted longer survival. Among clergy studies, 12 of 13 found that clergy survived longer than did comparison groups. The most consistent findings (besides lower clergy mortality) was that frequency of religious attendance predicted longer survival. All six of the six most recent and better designed studies reported such an effect - the size of which was roughly equivalent to not smoking cigarettes (adding as many as seven years to survival) [40-45].

In summary, the vast majority of studies - with notable exceptions [46] - tend to support the theoretical model presented in the third article of this series. In other words, religious beliefs and practices that are rooted within major religious traditions may impact physical health through a number of well-established psychological, social, and behavioral mechanisms.

\section{IMPLICATIONS FOR MEDICAL PRACTICE}

\section{Spiritual Needs of Patients}

If over 40 percent of medical patients in some areas of the country utilize religious beliefs as their primary way of coping with medical illness and another 50 percent use it in a secondary way, this underscores the importance and prevalence of spiritual needs during medical illness [47]. Such needs are found not only among patients in North Carolina. Kaldjian and colleagues [48] surveyed 90 HIV-positive patients at Yale-New Haven Hospital, finding that 98 percent believed in a divine being called "God," 84 percent expressed a personal relationship with God, and 82 percent said that their belief in God 
helped when thinking about death. In addition, however, 44 percent felt guilty about their HIV infection and 26 percent felt their disease was a form of punishment (17 percent a punishment from God). Only 30 percent, however, had spoken with a hospital chaplain.

Spiritual needs are also found among psychiatric patients, a group to whom clergy have traditionally had limited access. Fitchett and colleagues [49] at Chicago's Rush-Presbyterian Medical Center discovered that 88 percent of psychiatric inpatients had three or more current religious needs. Despite this, over three-quarters of these patients had not spoken with a clergyperson during their hospital stay. This figure contrasted sharply with only 19 percent of medical inpatients who had not spoken with clergy.

\section{Wishes of Patients}

As we debate the positive and negative effects of religion on mental and physical health, it is necessary to consider how patients feel about health care professionals addressing religious issues. While we do not always grant patients their wishes, health professionals should at least consider the wishes of patients in matters having to do with their health. If religion is how many patients cope with health problems and patients wish health providers to address spiritual needs, then this may be an important reason for doing so. If patients do not want physicians or other health providers to address spiritual or religious needs, then perhaps all such needs should be referred to clergy. Surveys indicate that physicians and patients have quite different views about this.

When Koenig and colleagues [50] asked a random sample of 160 Illinois physicians whether older patients during severe stress or near death would like their physicians to pray with them, 63 percent said that patients would not want this. In a separate study of 72 geriatric medical patients and senior center participants from the same geographical area [51], these investigators asked how subjects would feel about their physician praying with them during times of extreme physical or emotional distress. Over half of the patients (51 percent) indicated "yes, very much" and 27 percent indicated "yes, somewhat." Less than 20 percent indicated mixed feelings about physicians praying with them and only 5 percent were definitely opposed.

King and Bushwick [52] examined the religious beliefs and preferences of 120 patients admitted to Pitt Memorial Hospital in eastern North Carolina and 83 patients admitted to York Hospital in Pennsylvania. Ninety-eight percent of patients believed in God, 58 percent indicated their belief was "very strong," and 73 percent prayed daily or more often. When asked about whether or not they would like their physicians to pray with them, 48 percent said that they would (54 percent in the North Carolina sample and 40 percent in the Pennsylvania sample). Seventy-seven percent indicated that the physician should consider their 
patients' spiritual needs, and 37 percent wanted physicians to discuss religious issues more often with them. Not surprisingly, 80 percent said that their physicians had never or only rarely discussed religious beliefs with them.

Oyama and Koenig [53] interviewed 380 family medicine outpatients in Texas and North Carolina, finding that 43 percent were interested in knowing the religious beliefs of their doctors, 73 percent felt that patients should share their religious beliefs with doctors, and 67 percent felt that in certain circumstances they would like their physicians to pray with them. The religiosity of the patient was a

clear predictor of whether he or she wanted to know about the religious beliefs of the physician or share their own religious beliefs with the physician. Note also that Kaldijian and colleagues [48] found that 56 percent of 90 HIV-positive patients at Yale-New Haven Hospital believed that it was important to discuss spiritual needs with their physicians and 46 percent thought it would be helpful to pray with their physicians.

While physicians are not accustomed to addressing spiritual issues in clinical practice, many are at least open to addressing the religious needs of patients in certain circumstances. In a probability sample of 160 Illinois physicians, 92 percent felt that it was appropriate for the physician to address religious issues with patients under certain circumstances- 88 percent when the patient requested it, 82 percent if a request was implied, and 66 percent even if no request was made by the patient [50]. Less than one-third (31 percent) felt that the religious needs of patients should be left entirely up to the clergy. Comparable data are not available for psychiatrists or psychiatric patients.

\section{Role of the Physician}

There is little if any research that examines how physicians can appropriately and sensitively address religious/spiritual issues in medical or psychiatric practice. Thus, the recommendations below are largely based upon informal discussions between the author and colleagues on how a prudent clinician might proceed. These recommendations take into account that physicians in today's managedcare environment are unlikely to have much time to devote to religious or spiritual issues. Furthermore, these recommendations acknowledge that most physicians are unlikely to have the skills necessary to address religious or spiritual issues in any depth. The role of most physicians, then, lies primarily in assessment and orchestration of resources. Physicians who have training in this area may decide to go further than assessment and orchestration, although there are limits to how far physicians can or should go. Whatever action the physician takes must always be patient-centered. Finally, psychiatrists may need to proceed even more consciously than primary care physicians in addressing these issues, given boundary concerns with psychiatric patients [54]. 


\section{Assessment}

Physicians should consider taking a religious history on all patients with serious medical illness, which can be done as part of the social history. Such a history may be quite brief, particularly if the patient indicates that he or she is not religious; remember that many medical patients do not wish physicians to address religious issues. For most religious patients, however, taking such a history will be appreciated. A consensus panel of the American College of Physicians and Society of General Internal Medicine [55] recently suggested four questions that physicians might ask seriously ill patients:

- "Is faith (religion, spirituality) important to you in this illness?"

- "Has faith been important to you at other times in your life?"

- "Do you have someone to talk to about religious matters?"

- "Would you like to explore religious matters with someone?"

The physician should also ask whether religious concerns have been a source of stress or struggle for the patient.

\section{Orchestrator of Resources}

Having determined the patient's religious background and spiritual needs, the physician may now orchestrate resources to meet those needs as the patient directs. This may involve requesting that the nurse call the chaplain, the patient's minister, or some other religious leader or church friend, with the patient's permission. It may involve ensuring that religious reading materials are available, that there is access to religious TV programs, or that there is an opportunity to participate in religious services. In the busy hospital setting, the physician may need to ensure that the patient has uninterrupted time to pray with family, friends, or clergy. While all these activities may be delegated to others, the physician as orchestrator must ensure that they happen.

\section{Supporter of Patient Beliefs}

Considering interventions that the physician may choose to implement, the least invasive is simply to identify and support the religious or spiritual beliefs that the patient finds comforting. It is important to emphasize that the physician is supporting what the patient already finds helpful, not introducing new beliefs. By supporting the patient's religious beliefs and coping behaviors, the physician will reinforce such behaviors and perhaps increase their effectiveness in relieving anxiety and distress. Of course, discretion is always needed. If the patient's religious beliefs are bizarre or obviously conflicting with medical care, then the physician should neither support nor discourage such beliefs-but obtained assistance from a religious professional-preferably the patient's clergyperson. 
Psychiatrists should explore the meaning of the beliefs and how such beliefs are used defensively. This exploration, however, can be done in a supportive manner.

\section{Participator in Religious Practices}

If the physician has the same religious background as the patient and if the patient requests, then he or she may decide to participate in a religious activity like prayer with the patient. Psychiatrists need to be more cautious than primary care physicians in this regard. Prayer with the patient is the most likely religious activity that a physician will be asked to participate in. To ensure that this activity remains patient-centered, it is safest to encourage the patient to do the praying and the physician to participate silently, adding perhaps an "amen" at the end. If the physician believes it will comfort the patient, especially when the patient requests, the physician may decide to pray for the patient quietly on his or her own time, and inform the patient that he or she will be doing this. Knowing, for example, that one's surgeon will be praying for direction and success during an operation may help to relieve a religious patient's pre-surgical anxiety.

In some cases, the physician may wish to initiate a spoken prayer with the patient if the physician knows that this will bring comfort. Physician-initiated prayer, however, is more controversial because this introduces the risk that a religious activity may become physician-centered. For example, it may be quite difficult for a patient who does not wish to pray with a physician (a significant proportion of patients) to stop the physician if the latter initiates a prayer. Patients want to please their physician, particularly in this era of managed-care where patients may not have a choice of provider. The physician may control access to treatments and procedures that the patient desperately needs or wants. Thus, the patient may not feel free to refuse religious activities suggested by the physician for fear of offending him or her. It is essential that the physician be aware of the patient's religious background (to provide some sense of whether the patient would want this) and not proceed until explicit, uncoerced permission is obtained. For permission to be uncoerced, the patient must be completely free to refuse the activity without fear of negative repercussions. Knowing the patient's religious background well enough so as to be quite sure of their likely consent, then, is important.

\section{Prescriber}

If religious beliefs and activities are shown to maintain or improve mental or physical health, perhaps physicians should consider prescribing such activities to non-religious patients - just as they would prescribe cessation of smoking, regular exercise, or a balanced diet. In most cases, however, prescribing religious activities probably goes beyond the role of the physician. Furthermore, it is likely that if religious activities are chosen solely in order to benefit health, then they may not end up having that effect. Most of the research has shown that religious persons 
tend to have better mental and physical health than those not involved in such activities. Subjects in such studies, however, are generally involved in religious activities for religious reasons. The research does not show that becoming religious for health reasons alone will maintain health or cure disease.

On the other hand, there may be some circumstances - infrequent and carefully chosen - where the physician may encourage religious activities in an already religious patient. Take, for example, an older adult who at one point in life had been an avid churchgoer but who is now becoming increasingly socially isolated. Perhaps difficulties getting to church (because of physical disability, lack of transportation, etc.) or other barriers (unresolved problems with a church member or minister) have led to a decrease in attendance. If the physician knows that the patient would be receptive to a suggestion to increase religious participation, he or she may gently and sensitively suggest that the patient consider attending services more often - but not persist if any resistance is encountered. If the patient is receptive to such a suggestion, the physician may help the patient develop strategies to overcome barriers to religious participation. In general, however, such prescriptions for religious activity are risky and best avoided in non-religious patients or patients whose religious backgrounds are not thoroughly known by the physician.

\section{Referral}

Most physicians are not sufficiently trained to go much beyond taking a religious history, directing resources, and perhaps supporting patients' religious beliefs and practices. When spiritual needs are evident, it is probably best to refer patients to a clergyperson who is competently trained to meet those needs. Health professionals are often unaware of the extensive training that chaplains today receive. To become a certified chaplain in the Association of Professional Chaplains, an individual must graduate from college, complete three years of divinity school (for a Masters of Divinity), complete one to four years of clinical pastoral education (equivalent to an internship/residency), and pass both written and oral examinations. Chaplains, then, are the true professionals in this area.

Finally, most patients do not wish their physician to "trade" time spent dealing with necessary medical problems with time spent dealing with spiritual issues. If physicians address spiritual issues, they must be certain that medical issues and concerns are also competently and thoroughly addressed. Addressing spiritual issues, then, is something done "in addition to" addressing medical issues and may require an extra commitment of time.

\section{CONCLUSION}

There is little doubt that religion may in certain circumstances have adverse effects on health - particularly if beliefs are used to justify negative health 
behaviors or religious practices are substituted for traditional medical care. While more research and better designed studies are needed, the vast majority of research completed to date indicates that religious beliefs and practices are associated with better mental and physical health. These associations are as consistent and robust as associations between health status and other psychosocial variables (like social support, marital status, and certain health behaviors). Plausible psychological, social, and behavioral mechanisms exist by which religion can and should have a positive influence on health. Further research is needed to both replicate existing findings and more clearly define the mechanisms by which religion influences health and vice-versa. In particular, research is needed to help determine how to best apply these findings to clinical practice. Clinical applications have been suggested, although remain tentative until more evidence has accumulated. One thing is certain, however. Many of our patients are religious, use religious beliefs to cope with the stress of medical and psychiatric illness, and often have unmet religious or spiritual needs when they become physically or mentally ill. It would be sad indeed if clinicians ignored what might be a readily available, inexpensive, and powerful resource of comfort and healing.

\section{REFERENCES}

1. Koenig HG, McCullough M, Larson DB. Handbook of religion and health: A century of research reviewed. New York: Oxford University Press, 2001.

2. Turner JA, Clancy S. Strategies for coping with chronic low back pain: Relationship to pain and disability. Pain 1986;24:355-364.

3. Kabat-Zinn J, Lipworth L, Burney R. The clinical use of mindfulness meditation for the self-regulation of chronic pain. Journal of Behavioral Medicine 1985;8:163-190.

4. Florell JL. Crisis-intervention in orthopedic surgery: Empirical evidence of the effectiveness of a chaplain working with surgery patients. Bulletin of the American Protestant Hospital Association 1973;37(2):29-36.

5. Idler EL. Religious involvement and the health of the elderly: Some hypotheses and an initial test. Social Forces 1987;66:226-238.

6. Idler EL, Kasl SV. Religion, disability, depression, and the timing of death. American Journal of Sociology 1992;97:1052-1079.

7. Idler EL, Kasl SV. Religion among disabled and nondisabled elderly persons: Crosssectional patterns in health practices, social activities, and well-being. Journal of Gerontology 1997;52B:S300-S305.

8. Idler EL, Kasl SV. Religion among disabled and nondisabled elderly persons, II: Attendance at religious services as a predictor of the course of disability. Journal of Gerontology 1997;52B:S306-S316.

9. Idler EL. Religion, health, and nonphysical senses of self. Social Forces 1995; 74:683-704.

10. Medalie JH, Kahn HA, Neufled HN, Riss E, Goldbourt U. Five-year myocardial infarction incidence-II. Association of single variables to age and birthplace. Journal of Chronic Diseases 1973;26:329-349. 
11. Friedlander Y, Kark JD, Stein Y. Religious orthodoxy and myocardial infarction in Jerusalem-A case-control study. International Journal of Cardiology 1986;10:33-41.

12. Goldbourt U, Yaari S, Medalie JH. Factors predictive of long-term coronary heart disease mortality among 10,059 male Israeli civil servants and municipal employees. Cardiology 1993;82:100-121.

13. Oxman TE, Freeman DH, Manheimer ED. Lack of social participation or religious strength and comfort as risk factors for death after cardiac surgery in the elderly. Psychosomatic Medicine 1995;57:5-15.

14. Burell G. Group psychotherapy in Project New Life: Treatment of coronary-prone behaviors for patients who have had coronary artery bypass graft surgery. In Allan R, Scheidt S, editors, Heart and mind: The practice of cardiac psychology. Washington, D.C.: American Psychological Association, 1996, pp. 291-310.

15. Byrd RC. Positive therapeutic effects of intercessory prayer in a coronary care unit population. Southern Medical Journal 1988;81:826-829.

16. Leserman J, Stuart EM, Mamish ME, Benson H. The efficacy of the relaxation response in preparing for cardiac surgery. Behavioral Medicine Fall, 1989:111-117.

17. Thoresen CE. Long-term, 8-year followup of recurrent coronary prevention project: Invited Symposium. Uppsola, Sweden: 1st Conference of the International Society of Behavioral Medicine, June 14, 1990.

18. Zamarra JW, Schneider RH, Besseghini I, Robinson DK, Salerno JW. Usefulness of the transcendental meditation program in the treatment of patients with coronary artery disease. American Journal of Cardiology 1996;77:867-870.

19. Colantonio A, Kasl SV, Ostfeld AM. Depressive symptoms and other psychosocial factors as predictors of stroke in elderly. American Journal of Epidemiology 1992; 136:884-894.

20. McClelland DC. The effect of motivational arousal through films on salivary immunoglobulin A. Psychology \& Health 1988;2:31-52.

21. Koenig HG, Cohen HJ, George LK, Hays JC, Larson DB, Blazer DG. Attendance at religious services, interleukin-6, and other biological indicators of immune function in older adults. International Journal of Psychiatry in Medicine 1997; 27:233-250.

22. Lutgendorf S. IL-6 level, stress, and spiritual support in older adults. Psychology Department, University of Iowa and Iowa City. Personal communication, May 1997.

23. Woods TE, Antoni MH, Ironson GH, Kling DW. Religiosity is associated with affective and immune status in symptomatic HIV-infected gay men. Journal of Psychosomatic Research 1999;46:165-176.

24. Schaal MD, Sephton SE, Thoreson C, Koopman C, Spiegel D. Religious expression and immune competence in women with advanced cancer. Paper presented at the Meeting of the American Psychological Association, San Francisco, California, August 1998.

25. Katz J, Weiner H, Gallagher T. Stress, distress, and ego defenses. Archives of General Psychiatry 1970;23:31-142.

26. Kuemmerer JM, Comstock GW. Sociologic concomitants of tuberculin sensitivity. American Review of Respiratory Diseases 1967;96:885-892.

27. Comstock GW, Abbey H, Lundin FE. The nonofficial census as a basic tool for epidemiologic observations in Washington County, Maryland. In Kessler II, Levin ML, editors, The community as an epidemiologic laboratory: A casebook of community studies. Baltimore: Johns Hopkins Press, 1970:73-97. 
28. Naguib SM, Comstock GW, Davis HJ. Epidemiologic study of trichomoniasis in normal women. Obstetrics \& Gynecology 1966;27:607-616.

29. Naguib SM, Lundin FE, Davis HD. Relation of various epidemiologic factors to cervical cancer as determinants of a screening program. Obstetrics \& Gynecology 1966;28:451-459.

30. Kessler II, Kulcar Z, Zimolo A, Grgurevic M, Strnad M, Goodwin B. Cervical cancer in Yugoslavia. II. Epidemiologic factors of possible etiologic significance. Journal of the National Cancer Institute 1974;53:51-60.

31. Reynolds P, Kaplan G. Social connections and risk for cancer: Prospective evidence from the Alameda County Study. Behavioral Medicine Fall 1990: 101-110.

32. Dwyer JW, Clarke LL, Miller MK. The effect of religious concentration and affiliation on county cancer mortality rates. Journal of Health \& Social Behavior 1990; 31:185-202.

33. Enstrom JE. Health practices and cancer mortality among active California Mormons. Journal of the National Cancer Institute 1989;31:1807-1814.

34. Gardner JW, Lyon JL. Cancer in Utah Mormon men by lay priesthood level. American Journal of Epidemiology 1982;116:243-257.

35. Gardner JW, Lyon JL. Cancer in Utah Mormon women by church activity level. American Journal of Epidemiology 1982;116:258-265.

36. Ringdal G. Religiosity, quality of life and survival in cancer patients. Social Indicators Research, 1996;38:193-211.

37. LoPrinzi CL, Laurie JA, Wieand HS, Krook JE, Novotny PJ, Kugler JW, et al. Prospective evaluation of prognostic variables from patient-completed questionnaires. Journal of Clinical Oncology 1994;12:601-607.

38. Yates JW, Chalmer BJ, St. James P, Follansbee M, McKegney FP. Religion in patients with advanced cancer. Medical \& Pediatric Oncology 1981;9:121-128.

39. Collipp PJ. The efficacy of prayer: a triple-blind study. Medical Times 1969;97: 201-204.

40. Strawbridge WJ, Cohen RD, Shema SJ, Kaplan GA. Frequent attendance at religious services and mortality over 28 years. American Journal of Public Health 1997; 87:957-961.

41. Oman D, Reed D. Religion and mortality among the community-dwelling elderly. American Journal of Public Health 1998;88:1469-1475.

42. Hummer R, Rogers R, Nam C, Ellison CG. Religious involvement and U.S. adult mortality. Demography 1999;36:273-285.

43. Koenig HG, Hays JC, Larson DB, George LK, Cohen HJ, McCullough M, Meador K, Blazer DG. Does religious attendance prolong survival?: A six-year follow -up study of 3,968 older adults. Journal of Gerontology 1999;54A:M370-M377.

44. Musick MA, House JS, Williams DR. Attendance at religious services and mortality in a national sample. Presented at the Annual Meeting of the American Sociological Association, Chicago, August 6, 1999.

45. Glass TA, Mendes de Leon C, Marottoli MA, Berkman LF. Population based study of social and productive activities as predictors of survival among elderly Americans. British Medical Journal 1999;319:478-485.

46. Koenig HG. Religion and medicine I: Historical background and reasons for separation. International Journal of Psychiatry in Medicine 2000;30:385-398. 
47. Koenig HG. Religious beliefs and practices of hospitalized medically ill older adults. International Journal of Geriatric Psychiatry 1998;13:213-224.

48. Kaldjian LC, Jekel JF, Friedland G. End-of-life decisions in HIV-positive patients: The role of spiritual beliefs. AIDS 1998;12(1):103-107.

49. Fitchett G, Burton LA, Sivan AB. The religious needs and resources of psychiatric patients. Journal of Nervous \& Mental Disease 1997;185:320-326.

50. Koenig HG, Bearon L, Dayringer R. Physician perspectives on the role of religion in the physician-older patient relationship. Journal of Family Practice 1989;28:441-448.

51. Koenig HG, Smiley M, Gonzales J. Religion, health, and aging. Westport, CT: Greenwood Press, 1988:136-139.

52. King DE, Bushwick B. Beliefs and attitudes of hospital inpatients about faith healing and prayer. Journal of Family Practice 1994;39:349-352.

53. Oyama O, Koenig HG. Religious beliefs and practices in family medicine. Archives of Family Medicine 1998;7:431-435.

54. Meador KG, Koenig HG. Spirituality and religion in psychiatric practice: Parameters and implications. Psychiatric Annals 2000;30:549-555.

55. Lo B, Quill T, Tulsky J. Discussing palliative care with patients. Annals of Internal Medicine 1999;130:744-749.

Direct reprint requests to:

Harold G. Koenig, M.D.

Box 3040

Duke University Medical Center

Durham, NC 27710 